Rodrigo Romero CORRÊA ${ }^{1}$ André Luís do Valle ZOPPA² Luís Cláudio Lopes Correia da SILVA ${ }^{2}$

Wilson Roberto

FERNANDES ${ }^{3}$

Raquel Yvonne Arantes BACCARIN ${ }^{3}$

Rodrigo Silvério Ferreira da CRUZ

Denise Tabacchi FANTONI²

Correspondência para: RODRIGOROMEROCORRÊA Rua Barão de Ramalho, 350 - V. Scarpell Santo André-SP

romero@anhembi.br

Recebido para publicação: 17/05/2004 Aprovado para publicação: 01/06/2005

\title{
Estudo retrospectivo dos casos de enterolitíase e corpo estranho em intestino grosso de eqüinos, no período de janeiro de 1993 a janeiro de 2003
}

1 - Faculdade de Veterinária da Universidade Anhembi Morumbi, São Paulo - SP 2 - Departamento de Cirurgia da Faculdade de Medicina Veterinária e Zootecnia da Universidade de São Paulo, São Paulo - SP

3 - Departamento de Clínica Médica da Faculdade de Medicina Veterinária e Zootecnia da Universidade de São Paulo, São Paulo - SP

\section{Resumo}

Palavras-chave: Eqüinos.

No período de janeiro de 1993 a janeiro de 2003, foram realizados 195 Cirurgia. procedimentos cirúrgicos de abdômen agudo em eqüinos, no Serviço de Cirurgia de Grandes Animais do Hospital Veterinário da Faculdade de Medicina Veterinária e Zootecnia da Universidade de São Paulo. Dentre eles, foram diagnosticados 30 casos de enterolitíase e sete casos de corpo estranho, localizados em intestino grosso. Das 37 laparotomias, 35 foram realizadas em decúbito dorsal com acesso pela linha média e duas em estação com acesso pelo flanco. Os animais apresentaram idade variando de um a dezoito anos com média de oito anos, sendo 25 machos e 13 fêmeas. As formações e corpos estranhos apresentaram a seguinte localização: 13 (35,14\%) em cólon maior, 19 (51,35\%) em cólon menor, 03 (8,10\%) em cólon transverso e $02(5,41 \%)$ em cólon transverso e menor. Em relação à evolução, 23 $(62,16 \%)$ receberam alta e $14(37,84 \%)$ evoluíram para óbito (6) ou foram submetidos à eutanásia (8). Seis procedimentos de eutanásia foram realizados no período trans-operatório e dois no período pósoperatório. Dentre os animais que apresentaram evolução satisfatória, destacam-se um caso em que foram retirados sete enterólitos e outro em que a ponta de um prego que era o núcleo do enterólito se mantinha proeminente e em contato com a mucosa intestinal. Comparativamente às demais afecções do intestino grosso dos eqüinos e pela análise dos resultados obtidos neste estudo, conclui-se que os processos obstrutivos causados por enterólitos ou corpos estranhos apresentam prognóstico favorável.

\section{Introdução}

Como causas de dor abdominal em eqüinos, pode-se incluir as de origem no trato gastrointestinal e as de origem em outros sistemas diferentes do digestório. Diversas classificações podem ser feitas, sendo que cada área anatômica do sistema apresenta alguns tipos principais de alterações. Dentre as doenças do intestino grosso, destacam-se as torções, os deslocamentos, as compactações e as obstruções por corpos estranhos ou enterólitos.

O primeiro relato de enterolitíase em eqüinos foi feito em $1835^{1}$. O termo enterólito é derivado do grego entero, que significa intestinal, e lith, que significa pedra. Durante o século XIX foram feitos muitos relatos de casos de enterolitíases, primeiramente em cavalos de Miller. $\mathrm{Na}$ Alemanha, estes casos pareciam ser raros, sendo que os poucos casos ocorriam em cavalos desta raça. Nos Estados Unidos e França, nesta época, foram feitos alguns relatos desta condição. Com a mudança do 
século, houve uma aparente redução do número de casos na Europa ${ }^{2}$.

Os atuais avanços em técnicas anestésicas e cirúrgicas na espécie eqüina permitiram um maior índice de sucesso no tratamento de animais acometidos por enterolitíases ${ }^{3}$.

\section{Revisão Bibliográfica}

Os enterólitos, que são concreções formadas primariamente por fosfato de amônia e magnésio (estruvita) na forma de monohidrato ou hexahidrato ${ }^{2,4}$, podem obstruir a porção terminal do cólon dorsal direito, o cólon transverso ou o cólon menor. O mineral é depositado em camadas concêntricas ao redor de um núcleo que pode ser um corpo estranho (como pequenos pedaços de madeira, metais ou pedras). A amônia é continuamente produzida no cólon maior, e os fosfatos são encontrados em abundância na alimentação dos eqüinos ${ }^{4}$.

Em 1994 foi relatado um caso de enterólito em uma zebra que também era formado por fosfato de amônia e magnésio ${ }^{5}$. O dióxido de silicone, material encontrado normalmente nas pequenas pedras presentes nos pastos, e de fácil ingestão pelos eqüinos, tem sido o núcleo mais comumente encontrado nos enterólitos ${ }^{5}$.

Eqüinos que recebem grande quantidade de farelo de trigo em sua dieta têm maior predisposição para apresentar enterolitíases $^{5}$. O farelo de trigo possui grande concentração de proteína, fósforo e magnésio quando comparado aos outros alimentos fornecidos para cavalos ${ }^{6}$. A utilização de alfafa na alimentação de eqüinos que desenvolveram enterolitiase tem sido relatada $a^{6,7,8,9,10,11}$. Estudos realizados na Universidade de Califórnia revelaram que a concentração de magnésio presente na alfafa é aproximadamente seis vezes maior que as necessidades diárias de um cavalo. Além disso, o elevado teor protéico do feno de alfafa pode contribuir para a formação do cálculo, em decorrência do aumento da carga de nitrogênio derivada da amônia no intestino ${ }^{10}$. A quantidade de amônia presente na dieta pode ultrapassar a capacidade bacteriana intestinal de convertê-la em aminoácidos, e a amônia livre pode se combinar com os íons fosfato e magnésio e precipitar, formando a estruvita. A grande quantidade de proteína fornecida pelo feno de alfafa pode ultrapassar capacidade de conversão bacteriana, resultando na formação do enterólito ${ }^{2}$.

$\mathrm{O}$ pH intestinal pode variar de acordo com a alimentação fornecida aos animais. Cavalos alimentados com alfafa recebem grande quantidade de cálcio, que provoca alcalinização do pH do cólon. Esta alteração de pH é necessária para ocorrer cristalização dos sais de magnésio, fosfato e amônia ao redor do centro do enterólito ${ }^{12}$. Outros fatores que influenciam o $\mathrm{pH}$ intestinal ou a concentração de minerais no cólon devem ser considerados, como fatores genéticos ainda não determinados, dieta, microbiota intestinal, deficiências de absorção intestinal, capacidade de tamponamento do conteúdo intestinal e $\mathrm{pH}$ da água fornecida aos animais ${ }^{6}$.

Não existe predisposição para formação de enterólitos entre machos e fêmeas ${ }^{13}$. A idade dos eqüinos acometidos por enterolitíases pode variar entre 6 e 36 anos de idade, com média entre 7 e 11 $\operatorname{anos}^{8,14}$. A baixa incidência desta afecção em pacientes idosos ( $>14$ anos) atendidos em hospitais veterinários está relacionada à idade média de utilização dos cavalos e ao valor a ser investido no tratamento do animal ${ }^{2}$. Em estudo realizado em 1987, a média de idade dos cavalos com enterolitíases foi de 9,75 anos (+/- 4,09 anos), e os enterólitos são raramente encontrados em animais com menos de 4 anos $^{15}$.

Eqüinos de todas as raças podem ser acometidos, mas os animais da raça árabe são os mais comumente acometidos por enterolitíases ${ }^{14,15}$. Em 50 casos de enterolitíases estudados em 1981, $42 \%$ dos cavalos eram da raça Árabe, e $14 \%$ dos animais eram cruzamentos da raça Árabe. 
Esta maior incidência da raça pode também ser explicada por serem animais pertencentes a proprietários de maior poder aquisitivo, que podem arcar com os custos do procedimento cirúrgico ${ }^{13}$.

O formato dos enterólitos pode variar entre irregular, esférico, elíptico e nodular ${ }^{7}$. A textura dos enterólitos varia de acordo com a transformação da estruvita em vivianita, resultando em porosidade na arquitetura interna do enterólito ${ }^{6}$.

Provavelmente, os enterólitos tetraédricos indicam que concreções adicionais podem estar presentes, enquanto que as concreções esféricas podem indicar um único enterólito; entretanto, existem várias citações de mais de um enterólito esférico encontrado em um mesmo animal 12,15. O número de concreções pode variar de uma até várias em um mesmo animal. Grandes massas podem também ser encontradas, existindo relatos de enterólitos de $9 \mathrm{~kg}, 12 \mathrm{~kg}$ e até $19 \mathrm{~kg}^{12,15}$.

A forma e a localização da concreção irão ditar os sinais clínicos associados. Assim, os enterólitos de superfície grosseira e irregular encontrados no ceco e no cólon maior podem ter pouco ou nenhum sinal clínico, ou podem gerar episódios leves e recorrentes de cólica, em decorrência de irritação local da parede intestinal. Os enterólitos maiores e mais regulares causam caracteristicamente obstruções nas partes mais estreitas do intestino grosso, inclusive na flexura pélvica, cólon transverso e cólon menor. Os principias pontos de obstrução causada por enterólitos são o cólon transverso e o cólon menor, podendo também ocorrer no cólon dorsal direito, na flexura diafragmática e no reto ${ }^{2}$.

Os sinais clínicos observados em animais com enterolitíases podem iniciar antes de ocorrer obstrução intestinal. Em estudo realizado em 1999, 33 \% da população estudada apresentaram episódios de cólica em até um ano antes de serem submetidos a laparotomia exploratória, sendo a maioria desses sinais clínicos apresentados dois meses antes da cirurgia ${ }^{8}$.
Pequenos cálculos podem passar através das fezes sem produzir qualquer sinal clínico. Inapetência, hipomotilidade intestinal e diminuição da produção de fezes podem acompanhar os sinais de cólica ${ }^{12}$. Tipicamente os sinais de desconforto abdominal são leves e intermitentes, mantendo-se por vários dias, até que ocorra uma obstrução intraluminal completa que possa provocar dor moderada à severa e contínua ${ }^{9}$. A concreção inicialmente estimula a parede intestinal provocando o espasmo da alça e, conseqüentemente, obstrução aguda e ílio adinâmico. A pressão sobre a parede intestinal leva à hiperemia e congestão do segmento acometido, e conseqüentemente necrose. Caso a pressão local persistir, pode ocorrer ruptura da alça intestinal e iniciar um quadro de peritonite infecciosa ${ }^{16}$. As obstruções totais do cólon transverso ou do cólon menor causam dor aguda, de moderada à severa, não responsiva a analgésicos, com distensão abdominal produzida pela dilatação do cólon maior por gás ${ }^{2}$

As mucosas apresentam congestão discreta nas fases iniciais da enfermidade, e intensamente congestas nas obstruções totais, com evolução de 48 a 72 horas. O tempo de repleção capilar raramente ultrapassa 4 segundos, exceto nos casos em que a parede do intestino obstruído apresenta-se desvitalizada pela distensão causada pelo agente da obstrução. $\mathrm{O}$ abdome pode estar abaulado bilateralmente em sua região inferior e discretamente tenso. Os ruídos intestinais podem estar presentes, embora hipotônicos nos casos mais graves, e até exacerbados no início da manifestação de cólica ${ }^{11}$.

Em estudo estatístico realizado em 2000, os seguintes itens tiveram alta incidência nos casos de enterolitíases: dor abdominal com mais de 12 horas de evolução; febre; freqüência cardíaca maior que 60 batimentos por minuto; desidratação; ausência de borborígmos intestinais e concentração sérica de bilirrubina maior que $4,2 \mathrm{mg} / \mathrm{dl}^{7}$.

O diagnóstico definitivo de enterolitíases é baseado em uma laparotomia exploratória 
ou exame necroscópico. O histórico de passagem de enterólitos nas fezes é uma grande sugestão da referida alteração. A palpação do enterólito via transretal (embora nem sempre possível) é um forte indicador das enterolitíases. Deve-se lembrar que, freqüentemente, os pontos de localização dos enterólitos não são palpáveis por via transretal, e que a ausência de achados positivos na palpação retal não excluem a possibilidade de enterolitíases ${ }^{2}$.

A avaliação radiológica abdominal pode ser útil nos casos de enterolitíases. Em estudo realizado em 1987 , o exame radiográfico revelou 24 de 25 casos de enterolitíases que foram posteriormente confirmados por laparotomia exploratória. O uso de projeções laterais direitas permitiu a visualização do cólon maior e parte do cólon menor ${ }^{14}$.

A análise do líquido peritoneal pode refletir o curso da doença, mas algumas vezes pode-se não conseguir coletar amostras para análise macro e microscópica desse fluido. $O$ aumento da produção de líquido peritoneal e do número de leucócitos pode ser encontrado nos casos de infarto e necrose da parede intestinal, tornando-o mais turvo. A piora do quadro de compactação, com congestão venosa da porção intestinal acometida, diapedese de eritrócitos e leucócitos, poderão promover alterações maiores no líquido peritoneal, tornando-o de coloração âmbar a avermelhado ${ }^{4}$.

Os casos de obstruções de intestino grosso causadas por enterólitos requerem tratamento cirúrgico, onde deve ser realizada laparotomia e enterotomia para remover a causa da obstrução. O enterólito deve ser localizado e a técnica escolhida de acordo com a preferência do cirurgião?.

Em estudo realizado na Universidade da Califómia, dois ou mais enterólitos foram encontrados em $45 \%$ dos casos de enterolitíases. Cinqüenta e cinco por cento dos animais apresentavam somente um enterólito. Em 32 $\%$ dos casos, as obstruções foram provocadas no cólon dorsal direito, 22,5\% no cólon transverso e 45,1\% no cólon menor ${ }^{8}$.
O acesso cirúrgico pode ser feito pelo flanco, com o animal em posição quadrupedal, ou pela linha média, com o animal em decúbito dorsal. $\mathrm{O}$ acesso pelo flanco pode ser algumas vezes limitado, como nos casos de enterólitos localizados no cólon transverso; este segmento está firmemente aderido à parede abdominal dorsal, podendo resultar em dificuldade em exposição da alça e contaminação da incisão pelo flanco ${ }^{16}$.

O cirurgião deverá decidir se utilizará técnica de extração manual ou de hidropulsão. Existe uma técnica que cita a realização de um fluxo retrógrado de água através de uma enterotomia no cólon menor visando movimentar enterólitos alojados no cólon transverso. Existe também a possibilidade de realizar enterotomia caudal ou cranial ao ponto de obstrução causada pelo enterólito, e através dela remover a concreção?

Nos casos em que a alça acometida pela obstrução pode ser exteriorizada, podese fazer uma enterotomia sobre o ponto de obstrução, sendo esta incisão feita diretamente sobre a tênia antimesentérica ${ }^{17}$.

Uma técnica modificada para facilitar a remoção de enterólitos no cólon descendente foi descrita em 1998. De acordo com a técnica, uma pequena incisão de aproximadamente um centímetro deve ser feita através da camada seromuscular da tênia antimesentérica do cólon descendente, 10 a 15 centímetros aboral ao ponto de obstrução. A incisão deve ser prolongada cranialmente com tesoura de Metzembaum. Com bastante cuidado, deve-se fazer pressão através da parede da alça, movimentando o enterólito aboralmente, levando-o até um segmento que possa ser exteriorizado da cavidade abdominal, diminuindo o risco de contaminação ${ }^{18}$.

A enterorrafia pode ser feita de acordo com a preferência do cirurgião. O abdome deve ser cuidadosamente explorado antes da realização da laparorrafia, para assegurar que não existem enterólitos remanescentes ${ }^{2}$ 
O prognóstico é citado como reservado. Os melhores resultados são conseguidos quando o enterólito é removido antes de ocorrerem alterações severas da parede intestinal ${ }^{8}$. O prognóstico pode ser alterado de acordo com o estado do animal e da área intestinal no momento da cirurgia, bem como se é necessária realização de enterectomia ${ }^{2}$.

\section{Objetivo}

O objetivo do presente estudo é avaliar a freqüência de eqüinos submetidos a laparotomia que apresentavam enterolitíases ou corpos estranhos em intestino grosso, bem como suas principais características, em relação aos que apresentavam outros tipos de alterações.

\section{Materiais e Métodos}

Foram avaliados 195 casos de eqüinos com abdome agudo submetidos à laparotomia, no período de janeiro de 1993 até janeiro de 2003. Dentre estes casos, foram selecionados 37 animais que apresentaram obstrução de intestino grosso, sendo 30 causadas por enterólitos, 1 por enterólito e por corpo estranho e 6 causadas por corpos estranhos.

Estes casos clínico-cirúrgicos foram classificados de acordo com a idade, sexo, localização da obstrução, acesso cirúrgico utilizado e evolução dos animais.

\section{Resultados}

As obstruções de intestino grosso causadas por enterolitíase ou corpo estranho representaram $19 \%$ dos procedimentos cirúrgicos realizados em eqüinos com abdome agudo no período de janeiro de 1993 à janeiro de 2003. Destes animais, 81,08 $\%$ (30 casos) possuíam enterolitíase, 16,21\% (6 casos) possuíam corpo estranho em intestino grosso e $2,7 \%$ (1 caso) possuíam enterolitíase e corpo estranho. Dentre os casos de enterolitíases, destacaram-se um animal que possuía 7 enterólitos (Figura 1) e outro animal em que o núcleo de formação do enterólito era um prego que mantinha sua ponta exposta para a luz intestinal (Figuras 2 e 3 ).

De acordo com a idade, os animais foram divididos em 3 grupos distintos, onde os animais de 1 a 3 anos representaram 10,81\% (4 casos), de 4 a 8 anos 54,04\% (20 casos) e os animais com mais de 8 anos (13 casos) representaram 35,13\%.

Houve prevalência de animais do sexo masculino que apresentaram enterolitíases $(67,56 \%)$, enquanto que as fêmeas (12 animais) representaram $32,44 \%$ dos casos.

A localização dos corpos estranhos e enterólitos variaram de modo que $35,13 \%$ dos animais (13 casos) apresentaram obstrução em cólon maior, 51,35\% dos animais (19 casos) apresentaram obstrução em cólon menor, e em 5,4\% dos animais (2 casos) havia enterólitos em cólon maior e menor e, em $8,1 \%$ dos animais (3 casos), a localização da obstrução foi em cólon transverso.

Dentre as técnicas cirúrgicas utilizadas, a laparotomia com acesso pela linha média (linha alba) correspondeu à grande maioria dos casos $(94,59 \%)$, e o acesso cirúrgico pelo flanco correspondeu à somente 5,4\% dos casos.

Em relação à evolução dos casos, $62,16 \%$ dos animais receberam alta do hospital veterinário. Foram observados 1 caso de óbito no período pré-operatório $(2,7 \%), 1$ caso de óbito durante a recuperação anestésica $(2,7 \%)$ e 4 casos de óbito no período pós-operatório $(10,81 \%)$. Dentre as causas de óbito, destacaram-se o choque hipovolêmico e ílio adinâmico. Procedimentos de eutanásia foram realizados em 8 animais, sendo 6 destes procedimentos $(16,21 \%)$ realizados no período trans-operatório e 2 realizados no período pós-operatório. Como indicações para eutanásia destacaram-se os casos de rupturas intestinais e de segmentos de necrose intestinal.

\section{Discussão}

Nos últimos anos foi observado um 


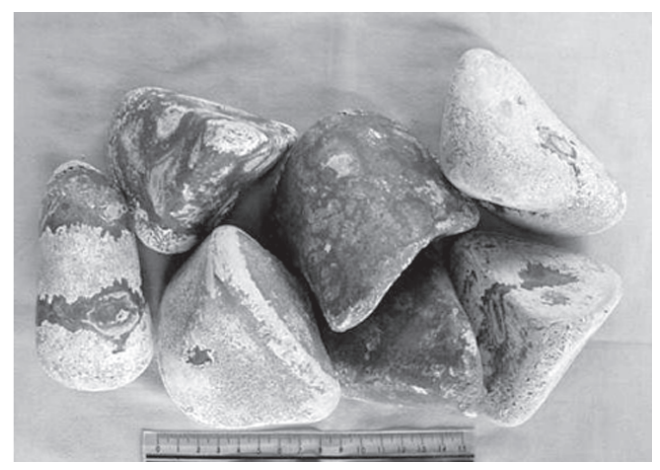

Figura 1 - Grupo de sete enterólitos retirados de um mesmo animal

aumento na incidência de casos de enterolitíases e obstruções por corpos estranhos, não só no Brasil, como em outras partes do mundo ${ }^{8}$. Este aumento pode ser devido ao maior número de animais estabulados, favorecendo a ingestão de corpos estranhos, ao tipo de alimentação fornecida aos animais, à conscientização dos proprietários em relação à gravidade dos casos de abdome agudo em eqüinos e à maior eficiência dos médicos veterinários em realizar o atendimento e a indicação cirúrgica do paciente com cólica. Não se pode deixar de enfatizar o grande papel realizado pelos exames auxiliares em confirmar o diagnóstico ou a indicação cirúrgica dos pacientes, como o exame radiológico abdominal, as provas bioquímicas hematológicas e do líquido peritoneal.

A média de idade dos animais acometidos por enterolitíases neste estudo foi de 8,87 anos, resultado inferior aos observados anteriormente ${ }^{3,15}$. O número de pacientes idosos atendidos em Hospitais Veterinários pode ser inferior à realidade devido à idade média de utilização dos cavalos e ao valor a ser investido no tratamento do animal ${ }^{2}$.

Uma grande variação foi observada em relação ao número de machos e fêmeas acometidos por enterolitíases e corpos estranhos intestinais. A proporção de machos apresentando estas alterações foi de $67,56 \%$ do total de animais em estudo, não acompanhando os resultados obtidos anteriormente $3,8,14$.

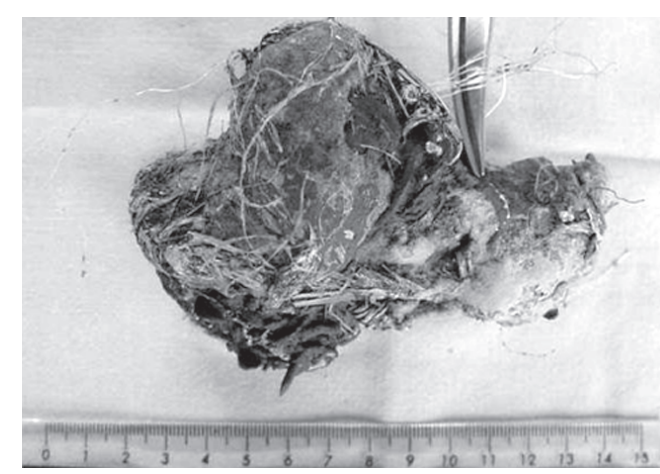

Figura 2 - Enterólito apresentando externamente a ponta de um prego

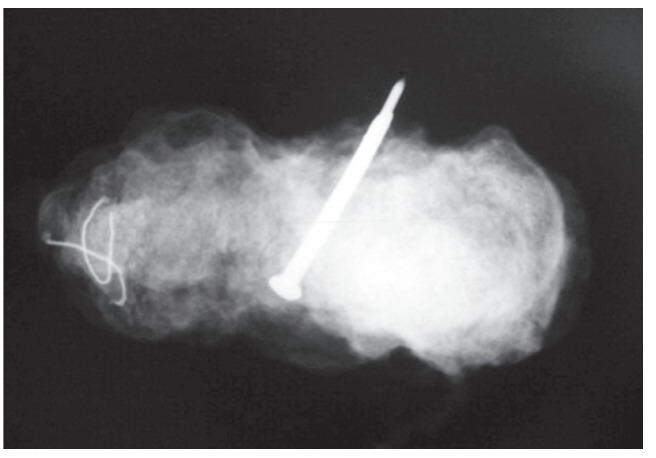

Figura 3 - Imagem radiográfica do enterólito apresentado na figura nº 2

Em relação à localização da obstrução, os enterólitos foram encontrados principalmente em cólon menor, seguido por obstruções em cólon maior e cólon transverso ${ }^{8}$. Isto pode ser explicado pela diferença presente em relação à luz intestinal do cólon menor e do cólon maior; enterólitos pequenos têm facilidade em se movimentar enquanto o diâmetro da alça intestinal é maior que seus diâmetros, e, quando atingem alças de menores diâmetros (como o cólon menor), não permitem a passagem do bolo fecal, produzindo distensão da alça e dor abdominal $^{8}$.

O principal acesso cirúrgico utilizado foi através da linha média abdominal, devido ao fato de não ter sido feito no período préoperatório o diagnóstico de enterolitíase ou corpo estranho intestinal, e estar sendo realizada uma laparotomia exploratória ${ }^{9}, 17$. $\mathrm{O}$ acesso pelo flanco foi realizado em somente dois casos, onde o diagnóstico da afecção foi firmado anteriormente à cirurgia, e o animal apresentava bom estado geral. 
O sucesso pós-operatório foi observado em $62,12 \%$ dos casos. Este valor pode ser alterado de acordo com o estado do animal e da área intestinal no momento da cirurgia, bem como se é necessária a realização de enterectomia ${ }^{2}$.

Como principais causas de eutanásia no período trans-operatório foram observados casos de ruptura e segmentos de necrose intestina ${ }^{19}$.

\section{Conclusão}

Os casos de obstrução de intestino grosso por enterolitíases e corpos estranhos vêm aumentando nos últimos anos, e merecem maior atenção por parte dos médicos veterinários de eqüinos. De acordo com estudos retrospectivos e com o presente estudo, têm-se atingido maior sucesso no tratamento cirúrgico destas alterações, justificando ainda mais a realização do mesmo. Técnicas alternativas para remoção de obstruções em pontos anatômicos considerados sem acesso cirúrgico já foram descritas, e cabe aos médicos veterinários conhecer estas técnicas e aplicá-las de forma correta.

Como forma de aumentar as taxas de sobrevivência pós-cirúrgica dos casos de enterolitíases, deve-se conscientizar os proprietários de eqüinos da necessidade de atendimento do animal por médico veterinário, e correta diferenciação dos casos de obstruções simples dos casos de obstruções por corpos estranhos ou enterolitíases. Desta forma, o tratamento cirúrgico pode ser instituído em um período mais curto de tempo, e o prognóstico pode melhorar significativamente.

O sucesso pós-operatório está sendo melhorado a cada ano devido à aplicação prática de estudos realizados previamente. $\mathrm{O}$ índice de sobrevivência é alto, atingindo valores muito bons ${ }^{2}$

\section{Retrospective study of enterolithiasis and foreign bodies found in the large intestine of horses (january 1993 to january 2003)}

\section{Abstract}

In the period from January 1993 to January 2003, 195 surgical procedures of equine acute abdomen were performed at the Service of Large Animal Surgery of the Veterinary Hospital of the School of Veterinary Medicine and Zootechnics of the University of São Paulo. From these 195 cases there were 30 enterolithiasis and seven foreign bodies located in the colon. Thirty-five out of 37 laparotomies were performed in dorsal recumbency, with access through the ventral midline and two were performed through the flank, with the animal in standing position. Of the 37 animals, 25 were male and 12 were females. Age varied from one to 18 years old with any average of eight years of age. Location of enteroliths and foreign bodies was as follows: $13(35.14 \%)$ in large colon, $19(51.35 \%)$ in small colon, $03(8.10 \%)$ in transverse colon and $02(5.41 \%)$ in both transverse and small colon. In regards to the clinical evolution, six were humenely eutmanized killed during surgery. From the 31 remaining, 23 (74,19\%) were discharged, $6(19,36 \%)$ died and $2(6,45 \%)$ were killed eutmanized during the post-operative period. Among those animals with satisfactory evolution two animals stand out. One of them had seven enteroliths and in the other, the nucleus of the mass was the tip of a nail, which protruded from the mass and was in constant contact with the intestinal mucosa. In spite of the large incidence of obstruction caused by enteroliths or foreign bodies in comparison of other studies, the prognosis of post-operative recovery is favourable.
Key-words:

Horse.

Surgery.

Entrolithiasis.

Foreign body.

Acute abdomen 


\section{Referências}

1 SPOONER, W. C. Intestinal Obstruction from a calculus. Veterinary Records, v. 1, p. 332-333.

2 MURRAY, R. C.; GREEN, E. M. CONSTANTINESCU, G. M. Equine enterolithiasis. The Compendium, v. 14, n. 8, p. 1104-1112, 1992.

3 FISCHER, A. T. Enterolithiasis. In: WHITE, N. A.; MOORE, J. N. Current practice of equine surgery. Philadelphia: JB Lippincott, 1990. p. 348-51.

4 BLUE, M. G.; WITTKOPP, R. W. Clinical and structural features of equine enteroliths. Journal of American Veterinary Medicine Association, v. 179, n. 1, p. 79-82, 1981

5 McDUfFEE, L. A.; SCHIFFMAN, P.; PARROT, J. J. Enterolithiasis in two zebras. Journal of American Veterinary Medicine Association, v. 204, n. 3, p. 430432, 1994.

6 HASSEL, D. M.; SCHIFFMAN, P. S.; SNYDER, J. R. Petrographic and geochemic evaluation of equine enteroliths. American Journal Veterinary Research, v. 62, n. 3, p. 350-358, 2001.

7 COHEN, N. D.; VONTUR, C. A.; RAKESTRAW, P. C. Risk factors for enterolithiasis among horses in Texas. Journal of American Veterinary Medicine Association, v. 216 , n. 11 , p. $1787-1794,2000$.

8 HASSEL, D. M.; LANGER, D. L.; SNYDER, J. R; DRAKE, C. M.; GOODELL, M. L.; WYLE, A. Evaluation of enterolithiasis in equids: 900 cases (1973 - 1996). Journal of American Veterinary Medicine Association, v. 214, n. 2, p. 233-237, 1999.

9 ROSS, M. W.; HANSON, R. R. Large intestine. In: AUER, J. A. Equine surgery. Philadelphia: Saunders, 1992. p. 392-393.

10 SNYDER, J. R.; SPIER, S. J. Moléstias do intestino grosso associadas à dor abdominal aguda. In: SMITH, B. P. Tratado de medicina interna de grandes animais. São Paulo: Manole, 1993. p. 703-704.

11 THOMASSIAN, A. Obstrução do cólon menor. In: THOMASSIAN, A. Enfermidade dos cavalos. São Paulo: Varela, 1996. p. 488-493.

12 MARIËN, T. Succesful surgical removal of eight enteroliths in a horse. Vlaams Diergeneeskundig Tijdschrift, v. 66, p. 231-234, 1997.

13 EVANS, D. R.; TRUNK, N. K.; HIBSER, T. E.; LONDON, C.A. diagnosis and treatment of enterolithiasis in equidae. Compendium Continuing Education Practise Veterinary. v 3, p. 383-391, 1981.

14 YARBROUGH, T. B.; LANGER, D.L.; SNYDER, J.R.; GARDNER, I.A.; O'BRIEN, T.R. Abdominal radiography for diagnosis of enterolithiasis in horses: 141 cases (1990-1992). Journal of American Veterinary Medicine Association, v. 205, n. 4, p. 592
595,1994

15 LLOYD, K.; HINTZ, H. F.; WHEAT, J. D. SCHRYVER, H. F. Enteroliths in horses. Cornell Veterinary, v. 77, p. 172-186, 1987.

16 BLUE, M. G. Enteroliths in horses - a retrospective study of 30 cases. Equine Veterinary Journal, v. 11, n. 2, p. 76-4, 1979 .

17 McILWRAITH, C. W.; ROBERTSON, J. T. Surgical corrections of displacements and abnormalities of the Large Intestine. In: McILWRAITH: C. W.; ROBERTSON J. T. Mcllwraith et turner's equine surgery: advanced techniques. 2. ed. Baltimore: Williams \& Wilkins, 1998. p. 314

18 HASSEL, D. M. YARBROUGH, T. B. A modified tenotomy technique for facilitated removal of Descending Colon enteroliths in horses. Veterinary Surgery, v. 27, p. 1-4, 1998.

19 GAY, C. C.: SPEIRS, V. C.; CHRISTIE, B. A.; SMYTH B.; PARRY, B. Foreign body obstruction of the Small Colon in six horses. Equine Veterinary Journal, v. 11, n. 1 , p. $60-63,1979$

20 KNOTTENBELT, D. C.; PASCOE, R. R. Condições do trato digestivo. In: KNOTTENBELT, D. C.; PASCOE, R. R. Afecções e Distúrbios do Cavalo. São Paulo: Manole, 1998. p. 63-64.

21 PELOSO, J. G.; COATNEY, R. W.; CARON, J. P.; STEFICEK, B. A. Obstructive enterolith in an 11-monthold miniature horse. Journal of American Veterinary Medicine Association, v. 201, n. 11, p. 1745-1746, 1992.

22 STRATTON-PHELPS, M.; FASCETTI, A. J. Nutritional therapy in gastrointestinal disease. In: ROBINSON, N. E. Current therapy in equine medicine. 5.ed. St. Louis: Saunders, 2003. p. 725-726. 